\title{
Considerations for Culturally Responsive Cognitive-Behavioural Therapy for Māori With Depression
}

\author{
Simon T. Bennett, ${ }^{1}$ Ross A. Flett, ${ }^{2}$ and Duncan R. Babbage ${ }^{3}$ \\ ${ }^{1}$ School of Psychology, Massey University, Wellington, New Zealand \\ 2 School of Psychology, Massey University, Palmerson North, New Zealand \\ 3 Person Centred Research Centre, Health and Rehabilitation Research Institute, Auckland University of Technology, Auckland, \\ New Zealand
}

\begin{abstract}
A strong case can be made for adapting cognitive-behavioural therapy (CBT) for ethnic and cultural minority groups. In North America, literature is readily available for CBT practitioners wishing to adapt their practice when working with ethnic minority groups (e.g., Latino, African-American, and Native American groups). In other countries such as New Zealand, literature of this sort is scarce, and the empirical foundation for CBT adaptation in these parts of the world is weak. This article documents the core tenets of an empirically validated CBT treatment protocol tailored for individual delivery to Māori clients suffering from depression in New Zealand and developed through consultation with an expert advisory group consisting of senior clinicians and Māori cultural experts. The result is a series of considerations for clinicians endeavouring to provide culturally responsive CBT with Māori clients, who are identified and organised into four domains. Two case studies are presented to illustrate the practical application of the proposed techniques. Links are made to international literature related to the adaptation of CBT in pursuit of cultural responsiveness.
\end{abstract}

Keywords: cognitive behavioural therapy, Māori, indigenous, depression

Literature informing clinicians regarding the cultural adaptation of evidence-based psychological therapy has been reasonably readily available in North America for over a decade. Hays (2016) encourages practitioners to consider the highly complex and multidimensional way that people conceptualise their identity when working therapeutically with diverse clients, in a book that is now in its third edition. Bernal and Domenech Rodriguez (2012) provide conceptual and methodological discussions to support their position that providing culturally adapted evidence-based practice (EBP) is a viable treatment approach when working with culturally diverse individuals such as African Americans, American Indians, and Chinese.

In 2007, Cognitive and Behavioral Practice published an article outlining important issues for clinicians to consider when providing cognitive-behavioural therapy (CBT) for depressed Hispanic clients (Interian \& DíazMartínez, 2007). A subsequent pilot study evaluated the efficacy of CBT adapted along the lines of the suggestions outlined in the original article (Interian, Allen, Gara, \&
Escobar, 2008). Using a similar methodology, this article documents the development of a culturally adapted CBT manual developed for use with the indigenous population of New Zealand; more specifically, Māori clients experiencing depression. In doing so, a series of cultural considerations for clinicians when working with Māori clients will be highlighted.

In the original CBT manual (Beck, Rush, Shaw, \& Emery, 1979) practitioners were advised that CBT should be confined to the types of clients who have been shown by empirical studies to respond well to this approach. Over subsequent years, studies have documented CBT as a highly effective treatment for depression. Despite the advice documented in the Beck et al. (1979) manual, these studies have generally lacked the statistical power to examine the response of ethnic minority groups (Miranda et al., 2005).

Sue and Zane (2006) considered the extent to which evidence-based practices have reduced ethnic disparities in the prevalence of mental illness and improved treatment effectiveness among ethnic minority groups. Their 
position was that psychological treatment should be guided by research evidence but that the gap between research and practice is far more pronounced regarding empirically supported therapies for racial and ethnic minority groups. They emphasised the need for continued research on treatment provision to ethnic minority groups.

Research by Organista, Munoz, and Gonzalez (1994) questions the cross-cultural validity of empirically supported treatments. The authors examined the cognitive behavioural treatment of depression among 175 lowincome outpatients. Sixty-five percent of this group were from ethnic minority groups (primarily Latin-American) and $44 \%$ were Spanish speaking. The observed reductions in depressive symptoms were not as large as had been expected from previous CBT outcome literature (Nietzel, Russell, Hemmings, \& Gretter, 1987). There were much higher drop-out rates $(58 \%)$ than those reported by the CBT treatment outcome literature; for example, Westbrook and Kirk (2005) reported a drop-out rate of 22.5\% out of 1,276 clients referred to a CBT clinic in Oxfordshire in the United Kingdom over an 11-year period (19871998); meanwhile, some studies have reported drop-out rates as low as 5\% (Rush, Beck, Kovacs, \& Hollon, 1977).

One possible explanation of these results is that CBT is simply less effective with, and less acceptable to, these cultural groups, at least when provided in an unmodified form. Supporting this theory, Kohn, Oden, Munoz, Robinson, and Leavitt (2002) reported greater reductions in depression for African-American women who received an adapted group CBT package as compared to those who received non-adapted group CBT. The adaptations employed by the researchers included the use of examples from African-American literature and anecdotes from African-American history, as well as specific modules on aspects of African-American life.

The two phases of research by Interian et al. (2008) and Interian and Diaz-Martinez (2007) provided strong support for the argument for adaptation. In adapting CBT for Hispanic clients, the authors emphasised an awareness of the client's worldview with regard to social structure and status. They stressed the importance of understanding the Hispanic concept of respeto (respect), which encourages deference toward people who are older, those in positions of authority, and parents. The concept of familismo, or a strong reliance on family, is another dimension emphasised by Interian and Diaz-Martinez (2007) when tailoring CBT for Hispanic clients, who suggest using familismo to provide motivation for behavioural change.

Adaptation has also been employed and endorsed in the Australasian region by Bennett-Levy et al. (2014). They provided targeted training in CBT to a group of Aboriginal-Australian counsellors and explored their perceptions of the usefulness of CBT with Aboriginals. The counsellors perceived that CBT was very effective, provided that it was adapted appropriately to fit the social and cultural context, with some indicating that utilising a visua or imagery component in CBT was particularly useful when working with this population.

\section{CBT and Māori}

Māori are the indigenous people of New Zealand, and according to 2006 census data, comprised $13.6 \%$ of New Zealand's population of over 4 million (Statistics New Zealand, 2006). Over the years subsequent to the European settlement of New Zealand in the late 1700s and early 1800s, Māori experienced considerable loss of land and autonomy (King, 2003). Contact with Europeans gave rise to a range of issues that have contributed to poor economic, social, and health outcomes for the Māori population (e.g., Durie, 2001; Walker, 2004).

In 2006, Te Rau Hinengaro: The New Zealand Mental Health Survey (Oakley-Browne, Wells, Scott, \& McGee, 2006) examined the prevalence of mental illness in the general New Zealand population. Depression was found to be a common disorder in New Zealand, and Māori experienced higher rates of depression than other ethnic groups (Baxter, Kingi, Tapsell, Durie, \& McGee, 2006).

In New Zealand, there is a great deal of rhetoric emphasising the importance of making CBT relevant to the unique cultural composition of the population. Blampied (1999) discussed the critical importance of CBT achieving a 'local accommodation' in New Zealand to ensure that it more effectively meets the needs of the Māori population. Evans (2002) echoed these views, suggesting that the psychological profession needed to adapt to become more culturally responsive to the aspirations and values of the Māori population.

Several Māori psychologists have discussed the use of CBT with Māori. McFarlane-Nathan (1993) recommended utilising culturally appropriate resources present within the community, acknowledging accepted Māori spiritual processes for healing and taking into account the acculturation factors encountered by Māori. Hirini (1997), on the other hand, raised several concerns regarding the degree of congruence that CBT shares with a Māori worldview. He cited the example that the promotion of assertiveness and independence, suggested by some to be a central aspect of CBT, may be a less relevant indicator of healthy social functioning for Māori. He also suggested that CBT might not fully account for systemic and historical issues that are experienced by Māori clients, such as discrimination and racism.

There are a number of parallels between the limitations identified by these authors regarding the utilisation of CBT with Māori and those identified in the wider international literature regarding applying the concepts of CBT to non-Western cultural groups. Hays and Iwamasa (2006) edited a book that thoughtfully offered a range of cultural considerations in the practice of CBT with diverse cultural groups, including those defined by ethnicity, religion, age, and sexuality. For example, Kelly (2006) 
emphasises the importance of understanding the American history of slavery when providing CBT for clients of African-American descent; Hays (2006) discussed the importance of appreciating spiritual perspectives in providing CBT for natives of Alaska; and Markus and Kitayama (1991) highlighted the distinct difference in attitudes between Asian and American culture with regard to individuality and the promotion of independence.

There is an overwhelming preference for CBT as the therapeutic modality of choice among New Zealand psychologists. Kazantzis and Deane (1998) found that a sample of 221 New Zealand psychologists used cognitive approaches more frequently than Australian, British, and North American psychologists. Fifty-five percent of New Zealand psychologists identified CBT as their primary therapeutic methodology. Another 33\% of respondents classified themselves as eclectic, of which over $80 \%$ identified CBT as one of their therapeutic modalities of choice. The great majority of Māori living in New Zealand and receiving psychological treatment are therefore likely to be receiving some form of CBT. This further underscores the need for research into the effective use of CBT with Māori.

Research examining the adaptation and clinical delivery of CBT to Māori are rare in New Zealand. Herbert (2001) compared an adapted CBT intervention designed to develop parenting skills with a standard parent training program. The adapted parent training program developed for Herbert's study recognised the importance of family interactions in child management, whereby whānau (family) can play an influential role in family decision making; they also incorporated a core set of values that were identified through a series of focus group interviews. These values included whakapapa (connection with ancestors), whānaungatanga (establishing familial connections), and awhinatanga (the act of being supportive). Herbert delivered these adapted parenting programs as well as the standard program to a cohort of Māori parents. Qualitative analysis showed that the clients who received the adapted programs experienced greater enjoyment, were more accepting of the intervention, and valued the program more highly.

New Zealand's residential correctional department (Department of Corrections) have been innovative in developing rehabilitation programs adapted to the cultural needs of Māori inmates, who constitute over $50 \%$ of the prison population (Ward, Day, \& Casey, 2006). One such example is the CBT program run at Te Piriti, one of the department's residential unit for sex offenders. Te Piriti delivers a treatment program modified to incorporate bicultural perspectives (Larson, Robertson, Hillman, \& Hudson, 1998) whereby all staff, residents, and visitors engage with the program via a traditional Māori welcome process, and receive treatment that is underpinned by important Māori concepts such as mutual support, love, and the sharing of genealogy. This program was found to be effective in preventing reoffending among both Māori and non-Māori offenders (Nathan, Wilson, \& Hillman, 2003).
With regard to treatment outcomes for Māori clients, Te Piriti compared favourably with its sister program, Kia Marama. Kia Marama delivered a similarly structured treatment package for sexual offenders, with significantly less integration of Māori concepts into their program. Māori men who completed the Te Piriti treatment program displayed a significantly lower sexual recidivism rate (4\%) than Māori men who completed Kia Mārama (14\%).

The literature suggests that the integration of Māori concepts and values when delivering therapy to Māori clients is a worthwhile endeavour, but recommendations generally come with a cautionary note. One study (Huriwai, Robertson, Armstrong, Kingi, \& Huata, 2001) integrated concepts of family participation and connection into a treatment program for Māori with issues of alcohol and drug abuse. It cautioned of the dangers of integrating cultural concepts into therapy on the basis of ethnicity alone. This could result in Māori clients being treated not as individuals, but in a 'stereotypical' manner that could lead to unrealistic expectations of the client.

Along similar lines, Durie (1995) talked about the existence of 'diverse Māori realities'. Many Māori have limited access to their culture, and for many, 'being Māori' may only form a small part of their overall identity. Therapy must be responsive to the individuality of the client to be effective (Constantino, Arnow, Blasey, \& Agras, 2005; Davila \& Levy, 2006; Stiles, Barkham, Twigg, Mellor-Clark, \& Cooper, 2006). Thus, the domains highlighted and discussed below should be viewed as considerations for the discerning clinician, as opposed to a checklist for treating Māori clients.

A comprehensive, individual CBT treatment program for depression was adapted to be specifically suitable for adult Māori with depression. The full methodology of that treatment study and the validation process for the treatment program is documented elsewhere (Bennett, Flett \& Babbage, 2014). In brief, statistical analyses indicated that the intervention had a significant impact in reducing depressive symptoms and negative cognition, as measured by the Beck Depression Inventory - 2nd Edition [BDI-II; Beck, Steer, Ball, \& Ranieri, 1996) and the Automatic Thought Questionnaire (ATQ; Hollon \& Kendall, 1980). Complementing that validation paper, this paper outlines in depth the adaptations made to traditional CBT, presenting both the consultation methodology, the rationale for the adaptations made, and laying out the adaptations themselves specifically enough to be able to be re-implement them in clinical practice or in future research.

\section{Method}

The cultural adaptation of CBT for individual delivery to adult Māori with depression was informed by literature related to the theory and practice of CBT, the primary researcher's clinical experience as a Māori senior clinical 


\section{Table 1}

Sample Case Vignettes to Illustrate Cultural Adaptations to CBT for Māori

\begin{tabular}{|c|c|}
\hline Case vignette \#1: Ella & te \#2: Manu \\
\hline $\begin{array}{l}\text { Ila is a 24-year-old Māori female with a primary diagnosis of major } \\
\text { depressive episode. Ella was raised primarily by her New Zealand } \\
\text { European mother and had little to do with her Māori father who left } \\
\text { Ella's mother when Ella was } 3 \text { years old. Subsequently she had } \\
\text { sporadic contact with her father throughout her childhood. Ella's } \\
\text { father provided minimal financial support, and as a result she and her } \\
\text { mother struggled to maintain a reasonable standard of living. Ella } \\
\text { developed negative core beliefs associated with a sense of being } \\
\text { 'unworthy' of love, as well as strong beliefs about the trustworthiness } \\
\text { of males. Her unhelpful coping strategies included a tendency to } \\
\text { avoid emotional intimacy in relationships and to seek validation } \\
\text { through physical intimacy with men. }\end{array}$ & $\begin{array}{l}\text { Manu is a 66-year-old Māori male with a primary diagnosis of major } \\
\text { depressive episode. Manu grew up speaking the Māori language } \\
\text { fluently and in a family in which a high premium was placed on } \\
\text { remaining connected to his Māori culture and supporting his family at } \\
\text { all costs. Manu's father was physically and emotionally abusive and } \\
\text { highly critical. He favoured Manu's older brother and pulled Manu out } \\
\text { of school at the age of } 14 \text { to send him to work to assist in paying for } \\
\text { the tuition fees of his older brother, who had commenced university. } \\
\text { Manu developed core beliefs including a strong sense of inferiority } \\
\text { and that others were 'better' than him. Manu coped with these beliefs } \\
\text { through significant avoidance }\end{array}$ \\
\hline
\end{tabular}

psychologist, as well as a consultation process as outlined below.

Seven clinical psychologists participated as advisors to assist in the adaptation of guidelines for an adapted CBT program for depression. All seven were experienced, working at a 'Consultant' level with a minimum of 10 years of applied clinical practice. Four consultants were of Māori descent and three were non-Māori New Zealanders. Three of the consultation group were female and four were male. All used CBT as part of their current practice when working with Māori clients.

These clinicians were identified for their experience and expertise in working with Māori and/or their advanced knowledge of CBT. Semi-structured interviews were conducted with the advisory group members; in three cases these were face to face, while four of the advisory group members provided both written and verbal input.

\section{Results}

The feedback regarding the limitations of CBT was generally consistent with the literature. The advisory group did not consider the limitations of CBT to be insurmountable or grounds for not using CBT with Māori clients. Some suggested that while the broader principles of CBT were applicable to Māori, limitations often arose from the manner in which these principles were applied. This initiated a wide-ranging discussion regarding process and structural adaptations to improve the relevance of CBT to Māori clients. This results section outlines the adaptations to CBT process and structure that emerged from the consultation process, categorised into broader cultural domains. In order to encapsulate the nature of the adaptations, two sample case vignettes are presented in Table 1 that will be discussed in relation to the domains presented.

\section{The Domain of Connectedness: Whakawhanaungatanga}

The domain of connectedness: Manu. As part of the initial stages of treatment, the clinician engaged in a process of self-disclosure, divulging information to Manu pertaining to his tribal affiliation at the first session. Through this process, a personal connection was identified between the client and therapist, as they both grew up in neighbouring regions of the same tribal area. This led to an extended discussion about significant connections to families in the area, and multiple commonalities were identified. Manu was pleased to have identified this connection and took the opportunity to demonstrate his depth of knowledge of the therapist's ancestry. This 'connection' between therapist and client manifested in a range of ways as therapy progressed and included Manu independently taking the initiative to conduct his own research on the therapist's family and providing him with a written note tracing his ancestry back several generations.

Whakawhanaungatanga has been described as the process of establishing family (whānau) relationships, literally by means of identifying, through culturally appropriate means, your linkage, engagement, connectedness, and commitment to other people (Bishop, 1998).

Consistent with research on therapeutic outcomes in other contexts (e.g., Falconnier, 2004; Gilbert \& Leahy, 2007), the therapeutic relationship was unanimously identified as a crucial factor in ensuring that CBT was effective when working with Māori clients. It was noted that the formality of the therapeutic relationship in Western models of psychotherapy could be excessively restrictive and prevent engagement at a more personal level with Māori clients. The inference then is that a therapist may need to take a substantially different approach in order to develop a positive therapeutic relationship with a Māori client.

CBT has been characterised by a more active deportment on the part of the therapist that allows for higher levels of emotional support and empathy than would be typical of the insight-oriented therapies (Keijsers, Schaap, \& Hoogduin, 2000). Despite this, therapist self-disclosure is a seldom-used technique in CBT; for instance, one study comparing $\mathrm{CBT}$ and insight-oriented therapies found no significant difference in the frequency of therapist selfdisclosures (Stiles, Shapiro, \& Firth-Cozens, 1988). Reservations have also been raised regarding the clinical benefits of self-disclosure by the therapist, with one review concluding that research findings suggested therapist selfdisclosure was not a powerful therapeutic intervention (Orlinsky \& Howard, 1986). These conclusions were, 
however, drawn from research conducted primarily with clients of Western European ethnicity.

In contrast, it emerged from the consultation process for this study that forming a personal connection with clients was crucial to achieving positive clinical outcomes. Advisors identified therapist self-disclosure as an effective and commonly used component of their clinical practice with Māori. The notion of utilising self-disclosure to facilitate a more personal therapeutic relationship with clients is consistent with current trends in international research, and several authors have found that a degree of therapist self-disclosure can have a positive impact on the therapeutic alliance and treatment outcome (e.g., Barrett \& Berman, 2001; Knox \& Hill, 2003). In the context of research into CBT with ethnic minority groups, the sharing of personal information between the therapist and client is encouraged as part of the initial engagement with Latino clients (Interian \& Díaz-Martínez, 2007; Organista, 2006).

The types of self-disclosures mandated by the therapists in the advisory group included tribal affiliation, working history, and family background. Where personal connections were made or similarities identified between the client and the therapist, these were acknowledged and further discussed rather than avoided. For example, if the client and therapist were from the same tribe, these similarities would be elaborated upon and explored with reference to any connections of significance. The goal of these disclosures was described as a crucial part of the process of whakawhanaungatanga and an integral part of working effectively with Māori clients.

As part of their overall assessment, some of the advisors described conducting a more thorough assessment of a client's tribal affiliation and ancestry. This would provide additional information regarding the extent to which the client identifies with their Māori ancestry and also provide a starting point to begin understanding the significance of various familial relationships. There was strong support for the use of a genogram to elucidate the nature and significance of client's wider family connections. Genograms have been used in the field of marital and family therapy for many years. Their primary purpose is to view problems across three or more family generations using symbols and a diagrammatic form viewing multiple contextual levels (Dosani, 2009). Genograms place importance on a wide range of constructs, including ethnicity, religion, race, class, and sexual orientation (Butler, 2008). For some of the advisory group, the use of a genogram formed an important part of the formulation process that is considered so crucial to the practice of CBT (Clark, Fairburn, \& Jones, 1997).

\section{The Domain of Spirituality: Te Taha Wairua}

The domain of spirituality: Ella. Due to her childhood experiences of having an absent father and being raised primarily by her non-Mãori mother, Ella felt little in the way of connection to her Māori heritage and acknowledged that during her early childhood she was ashamed of her 'Māori looks.' She resented her identity, wishing that she looked more like her mum. As Ella reached adulthood and became a parent herself, she began to experience a desire to find out more about who she was and in particular learn about her Māori background, so that she could pass this information on to her children. This goal was subsequently incorporated into therapy homework whereby an activity schedule was devised designed so that Ella could take some first tentative steps toward learning more about her tribal affiliations; and following on from this, further exploring the general history of her tribe. Activities included contacting local tribal authorities to learn more about the history of her tribe, identifying respected elders in her community who were able to share oral history about the area from which Ella's father hailed, and visiting locations of spiritual importance to her tribe (i.e., mountains and rivers).

The scientific, evidence-based foundations of CBT are often at odds with the perspective of Māori, who tend toward spiritual and metaphorical explanations for events (Hirini, 1997). Concerns regarding the omission of spirituality from CBT are shared by international experts, who suggest, for instance, that the inclusion of spirituality should form an important component of CBT with American-Indian clients (McDonald \& Gonzalez, 2006).

The incorporation of religion and client belief systems into the CBT treatment process has been considered elsewhere (e.g., D’Souza \& Rodrigo, 2004; Koenig, 2007). One study found that Christian clients who received a religious form of CBT improved significantly more than those who received a non-religious version (Propst, Ostrom, Watkins, Dean, \& Mashburn, 1992). Adaptations included providing clients with Christian religious rationales for the procedures, Christian arguments to counter irrational thoughts, and the use of Christian imagery. Paradis, Cukor, and Friedman (2006) described a similar range of considerations (such as the use of prayer in CBT) when treating Orthodox Jewish clients with anxiety disorders.

Te taha wairua, or the spiritual domain, is one of the four cornerstones of Māori health (the others being physical, psychological, and family; Durie, 1984). A number of the advisory group identified the exclusion of spirituality as a significant limitation of CBT when working with Māori.

The construct of taha wairua, while inclusive of religious beliefs, was seen as a broader concept. Implicit within this broader definition was the importance placed on connection and access to environmental resources of cultural significance, including meeting houses (marae), land (whenua), mountains (maunga), and rivers (awa); additionally, some of the advisory group emphasised an ancestral connection as being an important component of Māori spirituality.

The belief that all things living and non-living possess a spirit, held by some Native American cultures, has 
been documented extensively (e.g., Hays, 2006; Turner \& Pope, 2009). This animistic belief can be compared to the Māori concept of a Mauri. Mauri has been described as the essence or life force of something and is a quality ascribed not just to people, but entities such as mountains, lakes and rivers (Durie \& Hermansson, 1990). Understanding a client's level of access and connection to resources of cultural significance formed an important part of the assessment process for the advisory group, who pointed out that in their work with Mãori clients, therapeutic objectives often included setting goals and formulating plans to improve access to these resources.

The use of appropriate Māori proverbs (whakatauki) or Māori prayer (karakia) to commence and conclude sessions with Māori clients was unanimously endorsed. Rather than this being seen as a purely ritualistic or procedural process, the importance of selecting proverbs or prayer that had some relevance to the phase of treatment was emphasised, and some advisors assisted by providing particular proverbs that they utilised in their own work and considered to be meaningful in the context of mental health care. Some of the consultants suggested that the adapted treatment should give clients the opportunity to lead this process.

\section{The Domain of Extended Family: Te taha whānau}

The domain of extended family: Manu. During the course of treatment Manu invited his spouse Karen to attend every other session. Manu expressed that it was important to him that the therapist understood his role within his family and in particular his relationship with his siblings, and he believed that Karen was the best person to convey this information. Subsequently a 'Karen update' became a set agenda item every second session. During this part of the session, Karen would provide a family perspective on Manu's mood, as well as his general interactions with his family. Karen also became an active supporter of Manu completing his homework. She would remind him to complete an automatic thought record anytime that she noticed he had a significant change in mood state and was actively involved in social activation, goal setting and behavioural experiments that included such items as going out for dinner as a couple or exercising together.

The notion that family can play a protective role in relation to mental illness and stress has long been promoted by Māori academics (e.g., Diamond, 2005; Durie, 1999; Herbert, 2001; Pitama et al., 2007), and te taha whānau is another of Durie's (1984) cornerstones of Māori health. In his related commentary, Hirini (1997) pointed out that the individualised and thus less collective focus of CBT was a potential barrier to engaging effectively with Māori clients and their whānau. The individual focus of Western psychotherapies reflects the more individualistic and independent culture of Western society (e.g., Gelman, 2004). This has been contrasted with Eastern cultures that often place a greater emphasis on mutual dependence and loyalty to one's family (Toukmanian \& Brouwers, 1998).
Literature regarding the culturally responsive delivery of CBT emphasises that an awareness of where clients exist on the continuum between individualism and collectivism is crucial when challenging the veracity of automatic thoughts or assessing whether intermediate assumptions and core beliefs are maladaptive or in fact a product of a collective system of values. For example, Stipek (1998) found that Chinese students reported that they would experience greater levels of shame and guilt than American students were a family member found to have committed some kind of moral transgression. In a clinical context, an awareness of these cultural differences should inform work with Chinese clients to reduce the chances of misinterpretation and pathologising beliefs (e.g., 'the actions of my family are a direct reflection of me') that in certain cultural contexts may be entirely valid.

Similarly as a culture, Māori tend toward a collective notion of identity (Novitz, Willmott, \& Willmott, 1989). The findings from this study additionally endorsed a more inclusive approach to treatment with Māori clients. Suggestions included extending an invitation to participants in the initial appointment letter to bring whānau support to initial sessions and involving whānau as active participants in treatment objectives (e.g., participating in behavioural experiments).

\section{Whaikōrero - The Domain of Metaphor}

The majority of psycho-educational material utilised by clinical psychologists uses Eurocentric examples to illustrate important cognitive behavioural concepts such as the connection between thoughts and emotions. An example of this is the popular CBT manual Mind Over Mood (Greenberger \& Padesky, 2015). Mind Over Mood used a series of vignettes to illustrate the key tenets of CBT in an applied manner. However, the vignettes and associated characters tend to reflect mainstream cultural influences in the United States. While this may be an understandable reflection of the original target audience, this becomes a limitation when used beyond that context.

The use of metaphor is a commonly used and effective technique in the skilled application of CBT (Otto, 2000). The use of traditional cultural stories or proverbs to facilitate therapeutic change when conducting psychotherapy with minority ethnic groups is not a new notion, either internationally (e.g., Malgady, Rogler, \& Costantino, 1990) or with Māori clients (Cherrington \& Rangihuna, 2000). Interian and Diaz-Martinez (2007) describe the use of dichos, or proverbs used in the Spanish language, when providing CBT to Hispanic clients. They provide a number of examples of dichos that could be effective in conveying crucial principals of CBT.

The findings of this research strongly endorsed the use of 'culturally appropriate' metaphor in the form of Māori proverbs, also known as whakatauki, with most advisors indicating that it was a common component of their work with Māori clients. A series of appropriate proverbs 


\begin{tabular}{lc}
\hline Table 2 \\
Māori Proverbs Incorporated Into Adapted CBT for Māori \\
\hline Proverb & English Translation \\
\hline $\begin{array}{l}\text { He ao Te Rangi ka uhia, ma te huruhuru te } \\
\text { manu ka rere ai. }\end{array}$ & $\begin{array}{c}\text { As clouds bedeck the heavens, so do feathers } \\
\text { to enable birds to fly. } \\
\text { Positive feelings in your heart will enhance } \\
\text { your self-worth. }\end{array}$ \\
$\begin{array}{c}\text { Te tiro atu to kanohi ki tairawhiti ana tera whiti } \\
\text { te ra kite ataata ka hinga ki muri kia koe. }\end{array}$ & $\begin{array}{c}\text { Turn your face to the sun and the shadows } \\
\text { will fall behind you. }\end{array}$ \\
$\begin{array}{c}\text { Ki te whakaarohia ka taea. Ki te } \\
\text { whakaarohia rānei kāore e taea. He tika koe. }\end{array}$ & $\begin{array}{c}\text { If you think you can, or if you think you can't, } \\
\text { then yourect. }\end{array}$ \\
$\begin{array}{c}\text { Whāia te iti kahurangi. Ki te tūohu koe, me he } \\
\text { maunga teitei. }\end{array}$ & $\begin{array}{c}\text { Pursue excellence }- \text { should you stumble, let } \\
\text { it be to a lofty mountain. }\end{array}$ \\
Nā tō rourou, nā taku rourou ka ora ai te iwi. & $\begin{array}{l}\text { With your food basket and my food basket the } \\
\text { people will thrive. }\end{array}$ \\
\hline
\end{tabular}

were identified that had relevance to the therapeutic goals of CBT. Using culturally relevant examples were a common part of the practice of the advisory group, who used proverbs selected to reflect the focus of the session. Table 2 presents examples of Māori proverbs identified by the advisory group that share commonalities with the goals of CBT.

The advisory group reported using the four cornerstones of Māori health, as articulated by Durie (1984), in a visual form as part of their assessment and ongoing monitoring of progress with their Māori clients. They suggested utilising the metaphor of te whare tapa wha (literally 'the four walls of the house') as a means of considering the weaknesses and strengths of Māori clients across the four dimensions.

The metaphor of a whare or house was extended to the development of a cognitive formulation. It included an analogy between early life experiences and the 'foundation' of the house, as well as coping or protective strategies and the 'roof' of the house. Figure 1 depicts the diagrammatic format developed for use with Māori clients to collaboratively formulate the presenting problem, using the example of Ella to highlight the application of the model.

\section{Treatment Structure}

Informed by the cultural dimensions outlined above, a 12session CBT program was developed and organised into five progressive treatment phases, as depicted in Figure 2.

It is important to note that these phases were not mutually exclusive and were not necessarily delivered in a linear manner. For example, the process of building a relationship with the client was not restricted to early sessions but was a dynamic process that continued and evolved throughout the 12 sessions of therapy.

The program was intended to allow clinical judgment and flexibility to guide administration. For example, some participants rapidly mastered skills associated with a treatment phase and therefore were able to progress to the next phase earlier than other clients. Conversely, when participants experienced difficulty mastering techniques associated with a given phase (e.g., breathing exercises in phase three), additional time was spent perfecting these skills rather than progressing to the next phase prior to mastery.

Phase One: Whakawhanaungatanga - Building the relationship. This phase involved developing a positive therapeutic alliance and building rapport with the client via a range of culturally relevant processes, including therapist self-disclosure, exploration of family history, establishment of connections between therapist and client, and engaging with relevant family members.

Phase Two: Ngā Maramatanga - Building insights. This phase involved two main processes designed to increase client insight. First, a cognitive conceptualisation was developed and negotiated in consultation with the client, utilising the adapted framework of a meeting house, as shown in Figure 1. Second, this phase involved the provision of a range of psycho-educational material pertaining to CBT and depression, some of which was culturally adapted for a Māori audience. It included orientation to key CBT models of practice such as the 5-part model.

Phase Three: Whanonga Pai - Behaving effectively. This phase involved a range of primarily behavioural strategies designed to promote positive behaviour. It included an adapted activity schedule that was translated into the Māori language to monitor and increase client participation in activities that promote a sense of enjoyment and/or achievement. During this phase, clients commenced thought recording with a particular focus on how behavioural changes could result in changes to different elements of the 5-part model.

Phase Four: Whakaaro Pai-Positive thinking. Primarily, this phase focused on increasing the clients' awareness of their cognitive process and then employed progressive strategies to assist the client in challenging their own negative thinking by examining evidence for and against negative thoughts, and developing alternative thoughts in response to challenging situations.

Phase Five: Ora Pai-Staying well. This phase involved activities typical of the relapse prevention stage inherent in CBT. This phase involved a thorough review of insights 


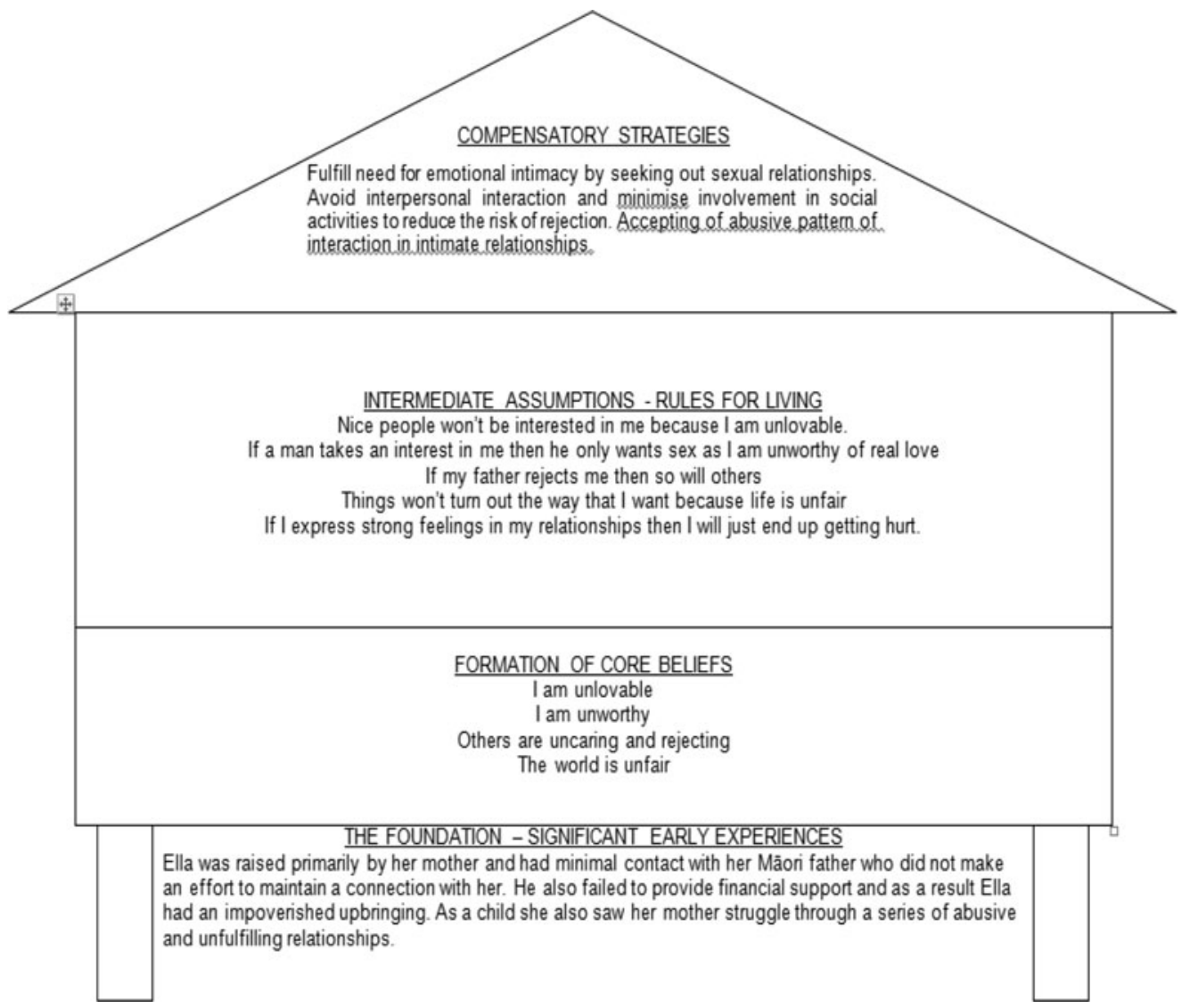

\section{Figure 1}

Formulation diagram adapted for use with Māori clients.

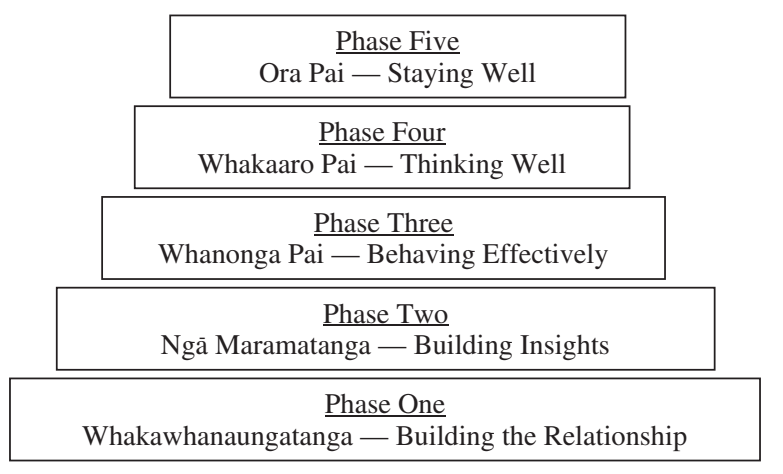

Figure 2

Treatment phases of CBT adapted for Māori clients.

developed throughout the therapy process and their linkage to the cognitive conceptualisation. In this stage, hypothetical management of future stressful circumstances was also employed.

\section{Conclusions and Recommendations}

In summary, the adaptation of CBT when working with culturally diverse populations is a minimum standard of best practice, and recommendations exist for a wide range of minority groups (e.g., De Coteau, Anderson, \& Hope,
2006; Gelman, 2004; Hays, 2006; Organista, 2006). Literature from New Zealand has highlighted limitations of CBT when treating Māori clients (e.g., Blampied, 1999; Evans, 2002), but despite the strong therapeutic predilection of New Zealand therapists toward CBT (Kazantzis \& Deane, 1998), literature documenting how CBT might be adapted for Māori clients is scarce. Providing CBT in a manner that is more closely aligned with the cultural values and ideals of the client may be an important step toward closing the considerable gaps in positive mental health that are frequently seen between minority ethnic populations and the dominant culture.

The current article has highlighted a series of cultural adaptations for consideration by clinicians who work with Māori clients. Clinicians considering incorporating these recommendations into their work with Māori clients, should do so in consultation with appropriate cultural supervision, and they should be underpinned by an understanding and appreciation of Māori cultural values.

The adaptations have been organised into four domains: connectedness, spirituality, extended family, and metaphor. The four domains have distinct parallels with the highly influential work of Durie $(1984,2007)$. This article, however, goes a step further in applying these domains within a cognitive behavioural framework and 
offering suggestions as to how these domains might be incorporated into a program of therapy.

The adaptations do not purport to be exhaustive, nor should they be considered a prescription for providing CBT to clients who identify as Māori; however, they do make a pragmatic contribution in an area that until now has remained somewhat neglected. Importantly, they also address the dire need of augmenting the empirical foundations on which psychologists working with Māori clients can base their work. Future research can continue to build on the practical resources that CBT practitioners have at their disposal when working with Māori clients to reflect the significant diversity of the Māori population, as well as adapting to the constantly evolving nature of culture.

\section{Acknowledgments}

The authors acknowledge the generous support of the Health Research Council of New Zealand, which supported this study through the award of a Clinical Research Fellowship to the first author.

\section{References}

Barrett, M.S., \& Berman, J.S. (2001). Is psychotherapy more effective when therapists disclose information about themselves? Journal of Consulting and Clinical Psychology, 69, 597-603.

Baxter, J., Kingi, T.K., Tapsell, R., Durie, M., \& McGee, M.A. (2006). Prevalence of mental disorders among Māori in Te Rau Hinengaro: The New Zealand Mental Health Survey. Australian and New Zealand Journal of Psychiatry, 40, 914-923.

Beck, A.T., Rush, A.J., Shaw, B.F., \& Emery, G. (1979). Cognitive therapy of depression. New York: Guilford Press.

Beck, A.T., Steer, R.A., Ball, R., \& Ranieri, W.F. (1996). Comparison of Beck Depression Inventories-IA and-II in psychiatric outpatients. Journal of Personality Assessment, 67, 588-597.

Bernal, G., \& Domenech Rodriguez, M.M. (Eds.). (2012). Cultural adaptations: Tools for evidence-based practice with diverse populations. Washington, DC: American Psychological Association.

Bennett, S.T., Flett, R.A., \& Babbage, D.R. (2014). Culturally adapted cognitive behaviour therapy for Māori with major depression. The Cognitive Behaviour Therapist. 7, e20.

Bennett-Levy, J., Wilson, S., Nelson, J., Stirling, J., Ryan, K., Rotumah, D., . . Beale, D. (2014). Can CBT be effective for Aboriginal Australians? Perspectives of Aboriginal practitioners trained in CBT. Australian Psychologist, 49, 1-7.

Bishop, R. (1998). Freeing ourselves from neo-colonial domination in research: A Māori approach to creating knowledge. International Journal of Qualitative Studies in Education, 11, 199-219.

Blampied, N.M. (1999). Cognitive-behavior therapy in Aotearoa, New Zealand. The Behavior Therapist, 22, 173-178.

Butler, J.F. (2008). The family diagram and genogram: Comparisons and contrasts. The American Journal of Family Therapy, 36, 169-180.
Cherrington, L., \& Rangihuna, D. (2000, June-July). Māori mythology in the assessment and treatment of Māori tamariki (children) and rangatahi (youth). Paper presented at the Joint RANZCP of Child and Adolescent Psychiatry Conference and Child and Adolescent Mental Health Conference, Auckland, New Zealand.

Clark, D.M., Fairburn, C.G., \& Jones, J.V. (1997). The science and practice of cognitive behavior therapy. Journal of Cognitive Psychotherapy, 11, 141-144.

Constantino, M.J., Arnow, B.A., Blasey, C., \& Agras, W.S. (2005). The association between patient characteristics and the therapeutic alliance in cognitive-behavioral and interpersonal therapy for bulimia nervosa. Journal of Consulting and Clinical Psychology, 73, 203-211.

D’Souza, R.F., \& Rodrigo, A. (2004). Spiritually augmented cognitive behavioral therapy. Australasian Psychiatry, 12, 148-152.

Davila, J., \& Levy, K.N. (2006). Introduction to the special section on attachment theory and psychotherapy. Journal of Consulting and Clinical Psychology, 74, 989.

De Coteau, T., Anderson, J., \& Hope, D. (2006). Adapting manualized treatments: Treating anxiety disorders among Native Americans. Cognitive and Behavioral Practice, 13, 304-309.

Diamond, P. (2005). Whanau healing: How can Māori culture improve mental health. Listener, 24.

Dosani, S. (2009). Genograms: Assessment and intervention. The British Journal of Psychiatry, 194, 95.

Durie, M. (1984). 'Te taha hinengaro': An integrated approach to mental health. Community Mental Health in New Zealand, 1, 4-11.

Durie, M. (1995). Ngā matatini Māori: Diverse Māori realities. A paper prepared for the Ministry of Health.

Durie, M. (1999). Kaumatuatanga reciprocity: Māori elderly and whanau. New Zealand Journal of Psychology, 28, 102-106

Durie, M. (2007). Counselling Māori: Marae encounters as a basis for understanding and building relationships. New Zealand Journal of Counselling, 27, 1-8.

Durie, M.H. (2001). Mauri ora: The dynamics of Māori health. Auckland, New Zealand: Oxford University Press.

Durie, M., \& Hermansson, G. (1990). Counselling Māori people in New Zealand [Aotearoa]. International Journal for the Advancement of Counselling, 13, 107-118.

Evans, I.M. (2002). Clinical psychology in early 21st century Aotearoa/New Zealand: Introduction to the special issue. New Zealand Journal of Psychology, 31, 50-52.

Falconnier, L.A. (2004). Socioeconomic status and the treatment of depression: The role of therapist attitudes, the therapeutic relationship, and addressing stressful life circumstances. Chicago: University of Chicago, School of Social Service Administration.

Gelman, C.R. (2004). Empirically-based principles for culturally competent practice with Latinos. Journal of Ethnic \& Cultural Diversity in Social Work, 13, 83-106.

Gilbert, P., \& Leahy, R.L. (2007). The therapeutic relationship in the cognitive behavioral psychotherapies. New York: Routledge. 
Greenberger, D., \& Padesky, C.A. (2015). Mind over mood: Change how you feel by changing the way you think. New York: Guilford Publications.

Hays, P.A. (2006). Cognitive-Behavioral therapy with Alaska people. In P.A.E. Hays \& G.Y.E. Iwamasa (Eds.), Culturally responsive cognitive-behavioral therapy: Assessment, practice and supervision. Washington, DC: American Psychological Association.

Hays, P.A. (2016). Addressing cultural complexities in practice: Assessment, diagnosis, and therapy (3rd edition). Washington, DC: American Psychological Association.

Hays, P.A., \& Iwamasa, G.Y. (2006). Culturally responsive cognitive-behavioral therapy: Assessment, practice, and supervision. Washington, DC: American Psychological Association.

Herbert, A.M.L. (2001). Whanau whakapakari: A Māori-centred approach to child rearing and parent-training programmes. Unpublished doctoral thesis, University of Waikato, Hamilton.

Hirini, P. (1997). Counselling Māori clients: He whakawhiti nga whakaaro i te tangata whaiora Māori . New Zealand Journal of Psychology, 26, 13-18.

Hollon, S.D., \& Kendall, P.C. (1980). Cognitive self-statements in depression: Development of an automatic thoughts questionnaire. Cognitive Therapy and Research, 4, 383-395.

Huriwai, T., Robertson, P.J., Armstrong, D., Kingi, T.P., \& Huata, P. (2001). Whanaungatanga - A process in the treatment of Māori with alcohol and drug-use related problems. Substance Use \& Misuse, 36, 1033-1051.

Interian, A., Allen, L.A., Gara, M.A., \& Escobar, J.I. (2008). A pilot study of culturally-adapted cognitive behavior therapy for Hispanics with major depression. Cognitive and Behavioral Practice, 15, 67-75.

Interian, A., \& Díaz-Martínez, A.M. (2007). Considerations for culturally competent cognitive-behavioral therapy for depression with Hispanic patients. Cognitive and Behavioral Practice, 14, 84-97.

Kazantzis, N., \& Deane, F.P. (1998). Theoretical orientations of New Zealand psychologists: An international comparison. Journal of Psychotherapy Integration, 8, 97-113.

Keijsers, G.P.J., Schaap, C., \& Hoogduin, C.A.L. (2000). The impact of interpersonal patient and therapist behavior on outcome in cognitive-behavior therapy: A review of empirical studies. Behavior Modification, 24, 264.

Kelly, S. (2006). Cognitive-behavioral therapy with African Americans. In P.A.E. Hays \& G.Y.E. Iwamasa (Eds.), Culturally responsive cognitive-behavioral therapy: Assessment, practice and supervision. Washington, DC: American Psychological Association.

King, M. (2003). The Penguin history of New Zealand. Auckland, New Zealand: Penguin Books.

Knox, S., \& Hill, C.E. (2003). Therapist self-disclosure: Researchbased suggestions for practitioners. Journal of Clinical Psychology, 59, 529-539.

Koenig, H.G. (2007). Spirituality and depression: A look at the evidence. Southern Medical Journal, 100, 737-739.
Kohn, L.P., Oden, T., Munoz, R.F., Robinson, A., \& Leavitt, D. (2002). Adapted cognitive behavioral group therapy for depressed low-income African American women. Community Mental Health Journal, 38, 497-504.

Larson, J., Robertson, P., Hillman, D., \& Hudson, S. (1998). Te Piriti: A bicultural model for treating child molesters in Aotearoa / New Zealand. In W. Marshall, S.M. Hudson, T. Ward \& Y. Fernandez (Eds.), Sourcebook of treatment programs for sexual offenders (pp. 385-398). New York: Plenum Press.

Malgady, R.G., Rogler, L.H., \& Costantino, G. (1990). Culturally sensitive psychotherapy for Puerto Rican children and adolescents: A program of treatment outcome research. Journal of Consulting and Clinical Psychology, 58, 704-712.

Markus, H.R., \& Kitayama, S. (1991). Culture and the self: Implications for cognition, emotion, and motivation. Psychological Review, 98, 224-253.

McDonald, J.D., \& Gonzalez, J. (2006). Cognitive-behavioral therapy with American Indians. In P.A.E. Hays \& G.Y.E. Iwamasa (Eds.), Culturally responsive cognitive-behavioral therapy: Assessment, practice and supervision. Washington DC: American Psychological Association.

McFarlane-Nathan, G.H. (1993). Cognitive behavior therapy and the Māoriclient. Paper presented at the Psychological Services Division Annual Conference, Wellington, New Zealand.

Miranda, J., Guillermo, B., Lau, A., Kohn, L., Hwang, W.-C., \& LaFromboise, T. (2005). State of the science on psychosocial interventions for ethnic minorities. Annual Reviews in Clinical Psychology, 1, 113-142.

Nathan, L., Wilson, N.J., \& Hillman, D. (2003). Te whakakotahitanga: An evaluation of the Te Piriti special treatment programme. Wellington, New Zealand: Department of Corrections, Psychological Services.

Nietzel, M.T., Russell, R.L., Hemmings, K.A., \& Gretter, M.L. (1987). Clinical significance of psychotherapy for unipolar depression: A meta-analytic approach to social comparison. Journal of Consulting and Clinical Psychology, 55, 156-161.

Novitz, D., Willmott, W.E., \& Willmott, B. (1989). Culture and identity in New Zealand. Lincoln, New Zealand: Manaaki Whenua Press.

Oakley Browne, M.A., Wells, J.E., Scott, K.M., McGee, M.A., for the New Zealand Mental Health Survey Research Team. (2006). Lifetime prevalence and projected lifetime risk of DSM-IV disorders in Te Rau Hinengaro: The New Zealand Mental Health Survey. Australian and New Zealand Journal of Psychiatry, 40, 865-874.

Organista, K.C. (2006). Cognitive-behavioral therapy with Latinos and Latinas. In P.A.E. Hays \& G.Y.E. Iwamasa (Eds.), Culturally responsive cognitive-behavioral therapy: Assessment, practice and supervision (pp. 73-96). Washington DC: American Psychological Association.

Organista, K.C., Munoz, R.F., \& Gonzalez, G. (1994). Cognitive Behavioral therapy for depression in low-income and minority medical outpatients: Description of a program and exploratory analyses. Cognitive Therapy and Research, 18, 241-259. 
Orlinsky, D.E., \& Howard, K.I. (1986). Process and outcome in psychotherapy. In S.L. Garfield \& A.E. Bergin (Eds.), Handbook of psychotherapy and behavior change (vol. 3, pp. 311381). New York: John Wiley.

Otto, M.W. (2000). Stories and metaphors in cognitive-behavior therapy. Cognitive and Behavioral Practice, 7, 166-172.

Paradis, C.M., Cukor, D., \& Friedman, S. (2006). Cognitivebehavioral therapy with Orthodox Jews. In P.A. Hays \& G.Y. Iwamasa (Eds.), Culturally responsive cognitivebehavioral therapy: Assessment practice and supervision. Washington, DC: American Psychological Association.

Pitama, S., Robertson, P., Cram, F., Gillies, M., Huria, T., \& Dallas-Katoa, W. (2007). Meihana model: A clinical assessment framework. New Zealand Journal of Psychology, 36, $118-125$.

Propst, L., Ostrom, R., Watkins, P., Dean, T., \& Mashburn, D. (1992). Comparative efficacy of religious and nonreligious cognitive-behavioral therapy for the treatment of clinical depression in religious individuals. Journal of Consulting and Clinical Psychology, 60, 94-103.

Rush, A.J., Beck, A.T., Kovacs, M., \& Hollon, S. (1977). Comparative efficacy of cognitive therapy and pharmacotherapy in the treatment of depressed outpatients. Cognitive Therapy and Research, 1, 17-37.

Statistics New Zealand. (2006). 2006 Census of Population and Dwellings. Wellington, New Zealand: Author.

Stiles, W.B., Barkham, M., Twigg, E., Mellor-Clark, J., \& Cooper, M. (2006). Effectiveness of cognitive-behavioral, personcentred and psychodynamic therapies as practised in UK National Health Service settings. Psychological Medicine, 36,555
Stiles, W.B., Shapiro, D.A., \& Firth-Cozens, J.A. (1988). Verbal response mode use in contrasting psychotherapies: A within-subjects comparison. Journal of Consulting and Clinical Psychology, 56, 727-733.

Stipek, D. (1998). Differences between Americans and Chinese in the circumstances evoking pride, shame, and guilt. Journal of Cross-Cultural Psychology, 29, 616.

Sue, S., \& Zane, N. (2006). How well do both evidence-based practices and treatment as usual satisfactorily address the various dimensions of diversity? In J.C. Norcross, L.E. Beutler, \& R.F. Levant (Eds.), Evidence-based practices in mental health: Debate and dialogue on the fundamental questions (pp. 329-374). Washington, DC: American Psychological Association.

Toukmanian, S.G., \& Brouwers, M.C. (1998). Cultural aspects of self-disclosure and psychotherapy. In S.S. Kazarian \& D.R. Evans (Eds.), Cultural clinical psychology: Theory, research and practice (pp. 106-124). Cary, NC: Oxford University Press.

Turner, S.L., \& Pope, M. (2009). Counseling with North America's indigenous peoples. In C.M. Ellis \& J. Carlson (Eds.), Cross cultural awareness and social justice in counseling (pp. 185-209). New York: Routledge/Taylor Francis Group.

Walker, R. (2004). Ka whawhai tonu matou: Struggle without end. Auckland, New Zealand: Penguin Books.

Ward, T., Day, A., \& Casey, S. (2006). Offender rehabilitation down under. Journal of Offender Rehabilitation, 43, 73-83.

Westbrook, D., \& Kirk, J. (2005). The clinical effectiveness of cognitive behaviour therapy: Outcome for a large sample of adults treated in routine practice. Behaviour Research and Therapy, 43, 1243-1261. 